ABSTRACT: $n$-Hexane neuropathy has been described after glue sniffing and industrial exposure. Onset may be subacute and reminiscent of Guil-

\section{Section Editors}

Robert C. Griggs, MD

Rochester, New York

Jerry R. Mendell, MD

Columbus, Ohio

Robert G. Miller, MD

San Francisco, California
lain-Barré syndrome. Although the primary pathology is axonal, electrophysiologic evaluation is frequently most remarkable for conduction slowing. We describe a patient with a severe subacute neuropathy following nhexane exposure via glue sniffing. Although symptoms worsened after termination of exposure ("coasting"), strength gradually improved to near normal. Sources of toxic exposure should be sought in all patients with subacute demyelinating neuropathies. () 1997 John Wiley \& Sons, Inc. Muscle Nerve 20: 1445-1450, 1997

Key words: n-hexane; hexacarbons; peripheral neuropathy; electroneuromyography; Guillain-Barré syndrome

\title{
n-HEXANE NEUROPATHY DUE TO RUBBER CEMENT SNIFFING
}

\author{
A. GORDON SMITH, MD, and JAMES W. ALBERS, MD, PhD*
}

Department of Neurology, University of Michigan Medical Center, 1500 East

Medical Center Drive, Ann Arbor, MI 48109, USA

Received 18 December 1996; accepted 31 M ay 1997

n-Hexane, an aliphatic hexacarbon with many industrial uses, is a well-known cause of peripheral neuropathy, both in industrial settings and in recreation glue sniffers. ${ }^{9,14,16,18,30,31}$ The typical clinical course is one of early sensory symptoms, followed by progressive weakness with a lower extremity predominance. Progression continues for some time after discontinuation of exposure ("coasting") and is followed by variable recovery. There is limited information in the literature regarding long-term electrophysiologic and clinical outcome. We report a patient with $n$-hexane neuropathy secondary to glue sniffing. Electrophysiologic evaluation and outcome are emphasized.

\section{CASE REPORT}

History. A 25-year-old man presented with complaints of progressive weakness, numbness, and pain. Four months earlier he developed right knee pain and weakness of the right foot. The pain progressed for 3 months when a cyst was removed from the right knee. His pain improved but he soon noted the gradual onset of bilateral leg weakness over 2 weeks requiring the use of a cane. $\mathrm{He}$ also noted diminished sensation in the feet, associated with lancinating pains. T wo weeks later bilateral hand numbness

${ }^{*}$ Correspondence to: Dr. J.W. Albers

CCC 0148-639X/97/111445-06

(C) 1997 John Wiley \& Sons, Inc. developed, causing difficulty with writing and buttoning shirts. There was a 25-pound weight loss. $\mathrm{He}$ was referred to us for treatment of acute inflammatory demyelinating polyradiculoneuropathy (Guillian-Barré syndrome), although his course was more characteristic of chronic inflammatory demyelinating polyradiculoneuropathy (CIDP). He had a history of schizophrenia, with auditory hallucinations requiring chronic neuroleptic use. Medications at the time of initial evaluation were fluoxetine, benztropine, and chlorpromazine. He initially denied current substance use but admitted to previous polysubstance use including crack cocaine and amphetamines. $\mathrm{H}$ is parents, however, described several months of repeated rubber cement inhalation ("huffing") with a 1-month history of heavy use, one bottle daily. $\mathrm{n}$-H exane was the primary ingredient of the rubber cement used.

Physical Examination. General physical examination was normal. Cranial nerve examination revealed only mild bifacial weakness. There was distal atrophy and fasciculations. Strength was graded as follows (MRC scale right/ left): neck flexors 5-, biceps 5-1 5 -, triceps 5- 5-, wrist extensors 5-15-, wrist flexors $4+4+$, finger extensors $4-4-$, thumb abduction $3 /$ 3 , first dorsal interosseous $3 / 3$, hip flexion $4-1$ 4-, knee extension and flexion 4-f 4-, ankle dorsiflexion $1 / 1$, ankle plantar flexion $4 / 4$, and toe extension $0 / 0$. Pin and temperature sensations were diminished to the midshin and midforearm, with 
diminished vibration to the knee symmetrically. Joint position sense was intact. Deep tendon reflexes were 1+ in the arms and absent in the legs. Plantar responses were flexor. He walked with the assistance of a cane.

Laboratory Evaluation. Laboratory evaluation included normal electrolytes, blood urea nitrogen, creatinine, calcium, magnesium, phosphate, liver function tests, and complete blood count. A sedimentation rate, serum protein electrophoresis, antinuclear antibody, urine porphyrin screen, and 24-h urine heavy metal assay were normal. Spinal fluid protein was $63 \mathrm{mg} / \mathrm{dL}$, with a glucose of 57 and one lymphocyte. A sural nerve biopsy was performed, revealing decreased density of large myelinated fibers with several focally swollen axons. Electron microscopy of the swollen axons revealed large collections of neurofilaments (Fig. 1).

Electrophysiologic Evaluation. Nerve conduction studies revealed borderline low sensory nerve action potential (SNAP) amplitudes with minimally prolonged sensory distal latencies. Compound muscle action potential (CMAP) amplitudes were diminished, motor distal latencies were prolonged, and motor conduction velocities were reduced (Table 1 ). There was conduction block in several locations: median nerve in the forearm, ulnar nerve in the forearm (Fig. 2), peroneal nerve across the knee, and tibial nerve in the leg. $F$ responses were absent. Needle electromyography revealed profuse positive waves and fibrillation potentials in limb muscles, particularly distally, but not in paraspinal muscles, with diminished recruitment of mildly polyphasic units. Limb temperature was maintained greater than $32^{\circ} \mathrm{C}$.

Clinical Course. After admission to the hospital and discontinuation of glue sniffing, weakness and numbness progressed over 1 week until he was wheelchair bound. At nadir, 3 weeks later, distal arm strength was graded as $2 / 2$, and only trace movements were present beneath the knee. Slow improve-

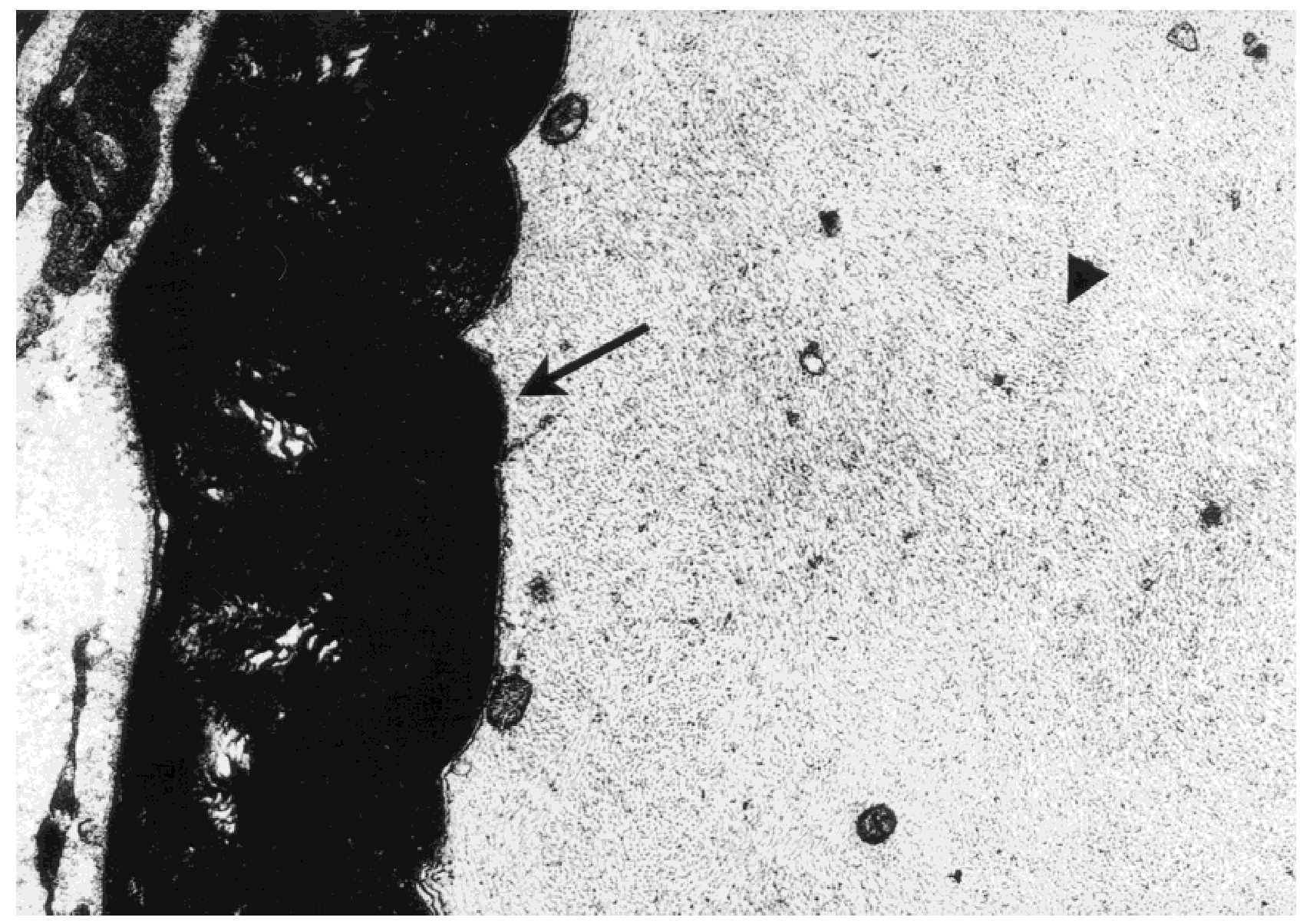

FIGURE 1. Electron micrograph of a swollen axon demonstrating massed neurofilaments (arrowhead) adjacent to myelin sheath (arrow). 


\begin{tabular}{llcrr}
\hline \multicolumn{4}{c}{ Table 1. Initial nerve conduction study. } \\
\hline Nerve & Recording site & Amplitude $(\mu \mathrm{V})$ & Distal latency $(\mathrm{ms})$ & Conduction velocity $(\mathrm{m} / \mathrm{s})$ \\
\hline Sural sensory & Lateral malleolus & $10(>6)$ & $3.0(<4.1)$ & $\mathrm{N} / \mathrm{A}$ \\
Median sensory & Second digit & $15(>15)$ & $3.5(<3.5)$ & $\mathrm{N} / \mathrm{A}$ \\
Ulnar sensory & Fifth digit & $9(>10)$ & $3.5(<3.5)$ & $\mathrm{N} / \mathrm{A}$ \\
Median motor & APB & $1.8(>4.0)$ & $6.9(<4.4)$ & $37(>49)$ \\
Ulnar motor & ADQH & $0.8(>6)$ & $5.9(<3.5)$ & $30(>49)$ \\
Peroneal motor & EDB & Absent & $\mathrm{N} / \mathrm{A} / \mathrm{A}$ & \\
Peroneal motor & AT & $0.6^{*}$ & $5.0^{*}$ & $14(>41)$ \\
Tibial motor & AH & $2.2(>3)$ & $5.4(<6.1)$ & $25(>41)$ \\
\hline
\end{tabular}

Normal values are in parentheses. Sensory conduction velocities in the forearm were not obtained. N/A, not applicable, APB, abductor pollicus brevis; $A D Q H$, abductor digit quinti hand; EDB, extensor digitorum brevis; $A T$, anterior tibialis; $A H$, adductor mallicus. *No normal values.

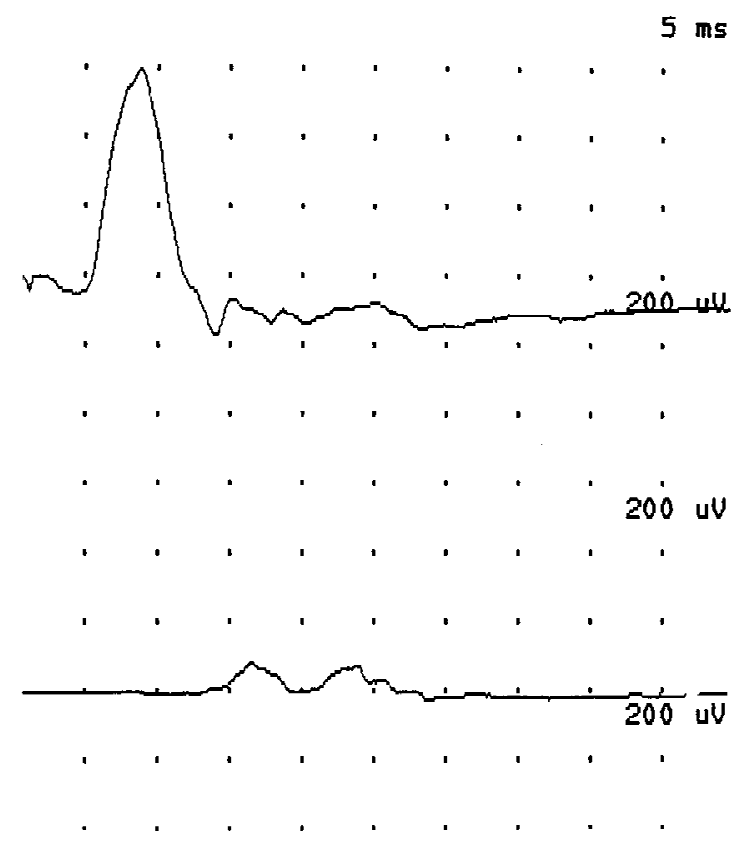

FIGURE 2. Partial motor conduction block of the ulnar nerve between the wrist (CMAP amplitude $0.7 \mathrm{mV}$ ) and elbow (CMAP amplitude $0.08 \mathrm{mV}$ ).

ment followed, and 1 year later strength was normal except for 5-5- ankle dorsiflexor strength; sensation was diminished distally in the hands and feet, and reflexes had returned. Electrophysiologic evaluations paralleled clinical recovery. There was an initial decrease in motor evoked amplitudes and motor conduction velocities 1 month after initial evaluation. With clinical recovery, however, all electrophysiologic parameters improved (Fig. 3). Eleven months after presentation nerve conduction studies had normalized in the arms and improved dramatically in the legs. The peroneal CMAP amplitude with recording over the extensor digitorum brevis was still reduced at $0.04 \mathrm{mV}$, although the CMAP amplitude recording over the anterior tibialis had returned to normal $(3.4 \mathrm{mV})$. Tibial and peroneal motor conduction velocities remained diminished ( 31 and 27 $\mathrm{m} / \mathrm{s}$, respectively), and the minimal latency of the tibial $F$ response was mildly prolonged at $57.8 \mathrm{~ms}$ (normal $<55 \mathrm{~ms}$ ).

\section{DISCUSSION}

Peripheral neuropathy is well described after exposure to $\mathrm{n}$-hexane. Industrial exposure has occurred in a number of settings including cabinet, ${ }^{10,19}$ laminating, ${ }^{32,33}$ pharmaceutical, ${ }^{34}$ adhesive bandage, ${ }^{29}$ raincoat, ${ }^{25}$ and printing ${ }^{5,6}$ industries, as well as in ball, ${ }^{11}$ adhesive paper, ${ }^{22}$ and sandal and shoe manufacturing. ${ }^{12,13,20,23,24}$ There are also reports of glue sniffers or "huffers" developing peripheral neuropathy. ${ }^{1-6,8}$ Severe cases related to industrial exposure are clinically indistinguishable from cases secondary to recreational inhalation. Numbness is typically noted in the feet and hands and rarely spreads beyond the knees or wrists. Weakness develops in the legs, then the arms, and tends to affect distal muscles most. In severe cases, marked distal atrophy and proximal weakness occur. Muscle cramping and weight loss are common. In many industrial cases the onset is gradual, with predominant sensory findings. ${ }^{26}$ In one large series of 93 patients, $57 \%$ had a sensory neuropathy, and only $8.6 \%$ also had amyotrophy. Distal lower extremity numbness was the first symptom in $88 \%$ of patients. ${ }^{13}$ In glue sniffers and severely affected industrial workers the onset may be subacute and reminiscent of Guillain-Barré syndrome. ${ }^{9,14,22,31}$ After exposure is terminated, patients may continue to worsen for many weeks, as in our patient. The "coasting" phenomenon is well described, both clinically and electrophysiological$\mid y,{ }^{11,14}$ and is observed in other toxic neuropathies including acrylamide, thalidomide, triorthocresylphosphate, ${ }^{11}$ and the multiple cranial neuropathies of trichloroethylene. ${ }^{3}$

The pathologic hallmark of $n$-hexane neuropathy is loss of large myelinated fibers with focally enlarged "giant" axons filled with neurofilaments and associated thinning of the overlying myelin. In addi- 

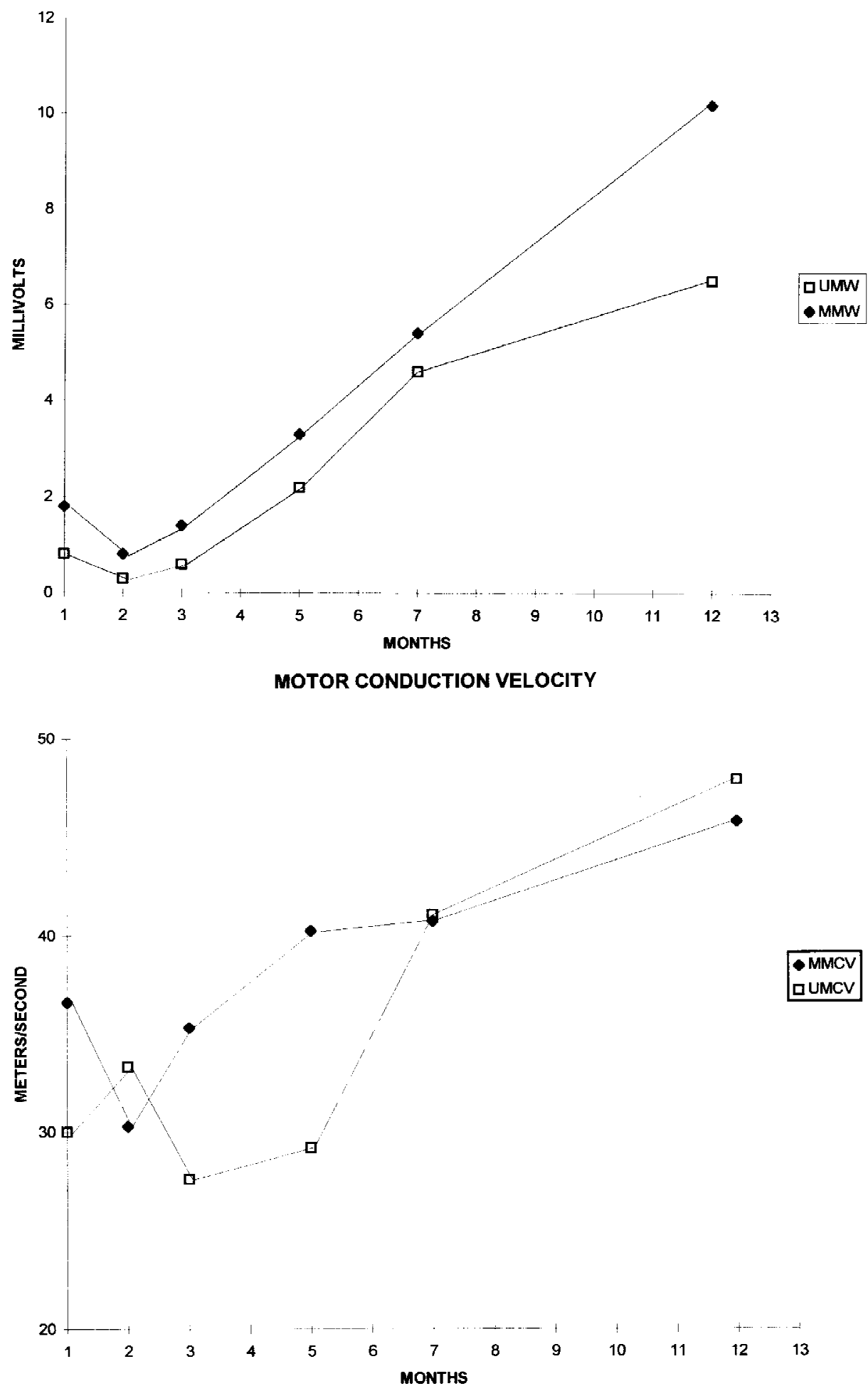

FIGURE 3. Ulnar and median CMAP amplitudes (A) and motor conduction velocities (B) at presentation (month 1) and at monthly follow-up. An initial decline is followed by gradual return to normal. MMCV, median motor conduction velocity; UMCV, ulnar motor conduction velocity. 
tion, paranodal myelin retraction and occasional segmental demyelination are observed. ${ }^{14,28,31}$ These features are the likely pathologic substrate for the electrophysiologic features of demyelination. Such findings are not unique to $n$-hexane neuropathy, having been described in methyl n-butyl ketone, acrylamide, triorthocresyl phosphate, and inherited giant axonal neuropathy. ${ }^{7,31}$ Similar axonal enlargement of a lesser degree may be seen after exposure to vinca alkaloids and colchicine. ${ }^{31}$ Schaumburg has suggested that axonal swellings begin in distal but nonterminal regions in a multifocal fashion, with subsequent spread to more distal and proximal segments and breakdown of nerve fibers distally. ${ }^{27}$ Based on pathologic evidence, the primary lesion in $\mathrm{n}$-hexane neuropathy is axonal, beginning distally with proximal spread, with secondary myelin changes. The exact mechanism is uncertain, although it is speculated that neurofilaments are the primary site of injury. The active metabolite is thought to be 2,5 hexanedione.

Electrophysiologic findings depend on the neuropathy's severity. One study of 20 industrial workers exposed to $n$-hexane with normal neurologic examinations and without neuropathic symptoms revealed normal nerve conduction velocities and $\mathrm{F}$ responses, but diminished SNAP amplitudes compared to agematched normals. ${ }^{5,21}$ Similar findings have been reported in patients without neurological disease exposed to n-methyl butyl ketone. ${ }^{1}$ of 56 workers exposed to $n$-hexane in an offset printing shop, $46 \%$ had subclinical peripheral neuropathy evident on nerve conduction studies, with markedly diminished SNAP amplitudes, diminished motor conduction velocity, mildly prolonged motor distal latencies, and reduced CMAP amplitudes. Among those with symptomatic neuropathy, motor nerve conduction velocities were markedly slowed. There was no relationship between duration of employment and development of neuropathy, suggesting that host factors such as individual variability in the hepatic $p-450$ system play a role. ${ }^{5}$ Many others have emphasized the reduction in motor conduction velocities in severely affected patients. $5,9,11-14,16-18,22,25,31$ Motor conduction velocities are slowest distally, with only mildly slowed proximal conduction velocity (e.g., between the neck and axilla). F waves are usually absent. ${ }^{17}$

Conduction block was observed in our patient and has been described by several others. ${ }^{4,15,17} \mathrm{Us}$ ing the criteria of Asbury and Cornblath, ${ }^{2}$ our patient met formal criteria for a primary demyelinating neuropathy. Among 27 neuropathy patients with industrial exposure, $67 \%$ had diminished conduction velocity in two or more nerves, $74 \%$ had partial conduction block or temporal dispersion in one or more motor nerves, $78 \%$ had two or more prolonged distal latencies, and $59 \%$ had absent or prolonged $\mathrm{F}$ responses in two or more locations. All four criteria for acquired demyelinating neuropathy were met by $37 \%$, while $26 \%, 19 \%$, and $15 \%$ met three, two, and one criteria, respectively. ${ }^{17} \mathrm{~N}$ eedle electromyography reveals fibrillation potentials and positive waves in involved distal muscles. While electrophysiologic features of demyelination are frequently prominent, the progression from reduced sensory evoked amplitudes to reduced motor evoked amplitudes and reduced motor conduction velocities indicate a primary axonal pathology, in accordance with pathological findings.

Prognosis for recovery from $n$-hexane neuropathy depends on the severity, with excellent clinical outcome in most patients with sensory neuropathy. Among 93 industrial workers, 57\% of whom had a sensory neuropathy, 34\% a sensorimotor neuropathy, and $9 \%$ amyotrophy, 92\% achieved a full recovery after 4 years, with the remaining patients left with only sensory abnormalities. ${ }^{13}$ There are relatively few data on recovery in severely affected huffers, however. Among 3 huffers unable to walk at the peak of their neuropathy, 2 recovered independent ambulation with persistent footdrops, and 1 achieved full recovery. ${ }^{14,15,31}$ Electrophysiologic recovery paralleled clinical improvement. ${ }^{15}$

Several aspects of our patient are of interest. Unlike most cases of industrial n-hexane neuropathy, he developed severe weakness, similar to other reports of n-hexane neuropathy in glue sniffers. Despite primarily axonal pathology, nerve conduction abnormalities met formal criteria for a primary demyelinating neuropathy, leading to the erroneous diagnosis of acute inflammatory demyelinating polyradiculoneuropathy. $\mathrm{n}-\mathrm{H}$ exane exposure was evident only after direct, separate questioning of his parents concerning substance abuse and toxic exposure. Sources of toxic exposure should be sought in any patient with a subacute neuropathy with demyelinating features on nerve conduction studies and distal denervation on needle electromyography. While there are minimal prognostic data in the literature, our experience demonstrates excellent clinical and electrophysiologic recovery, despite severe weakness and denervation.

\section{REFERENCES}

1. Allen N, Mendell JR, Billmaier DJ, Fontaine RE, O'Neill J: Toxic polyneuropathy due to methyl-n-butyl ketone: an industrial outbreak. Arch N eurol 1975;32:209-219. 
2. Asbury AK, Cornblath DR: Assessment of current diagnostic criteria for Guillain-Barré syndrome. Ann Neurol 1990; 27( suppl):21-24.

3. Buxton $\mathrm{PH}, \mathrm{H}$ ayward $\mathrm{M}$ : Polyneuritis cranialis associated with industrial trichlorethylene poisoning. J Neurol Neurosurg Psychiatry 1967;30:511-518.

4. Chang AP, England JD, Garcia CA, Sumner AJ: Multifocal conduction block in $\mathrm{n}$-hexane polyneuropathy [abstract]. M uscle N erve 1996;19:1207.

5. Chang $C M, Y u C W$, Fong $K Y$, Leung SY, Tsin TW, Yu YL, Cheung TF, Chan SY: n-H exane neuropathy in offset printers. J Neurol Neurosurg Psychiatry 1993;56:538-542.

6. Chang Y: Neurotoxic effects of $n$-hexane on the human cerebral nervous system: evoked potential abnormalities in $n-$ hexane polyneuropathy. J N eurol N eurosurg Psychiatry 1987;50: 269-274.

7. Davenport JG, Farrell DF, Sumi SM: "Giant axonal neuropathy" caused by industrial chemicals: neurofilamentous axonal masses in man. N eurology 1976;26:919-923.

8. Ehyai A, Freemon FR: Progressive optic neuropathy and sensorineural hearing loss due to chronic glue sniffing. I N eurol Neurosurg Psychiatry 1983;46:349-351.

9. Gonzales E, Downey J: Polyneuropathy in a glue sniffer. Arch Phys M ed 1972;53:333-337.

10. Herskowitz A, Ishii N, Schaumburg H : n-H exane neuropathy. N Engl J M ed 1971;285:82-85.

11. Huang CC, Chu NS, Cheng SY, Shin TS: Biphasic recovery in n-hexane polyneuropathy. Acta N eurol Scand 1989;80:610-615.

12. Iida M, Yamamura $Y$, Sobue I: Electromyographic findings and conduction velocity on $\mathrm{n}$-hexane polyneuropathy. Electromyography 1969;9:247-261.

13. Iida $\mathrm{M}$ : Neurophysiological studies of $\mathrm{n}$-hexane polyneuropathy in the sandal factory. Electroen cephalogr Clin N europhysiol 1982;36( suppl) :671-681.

14. Korobkin R, Asbury AK, Sumner AJ, Nielson SC: Glue-sniffing neuropathy. Arch N eurol 1975;32:158-162.

15. Kuwabara S, Nakajima M, T suboi Y, H irayama K: Multifocal conduction block in $\mathrm{n}$-hexane neuropathy [letter]. Muscle Nerve 1993;16:1416-1417.

16. Matsumura M, Inoue N, Ohnishi A: Toxic polyneuropathy due to glue-sniffing. Clin Neurol 1972;12:290-296.

17. O ge AE, Yazici J, Boyaciyan A, Eryildiz D, Ornek I, Konyalioglu R, Cengiz S, Oksak O, Asar S, Baslo A: Peripheral and central conduction in $\mathrm{n}$-hexane polyneuropathy. M uscle N erve 1994;17:1416-1430.

18. Oh SJ, Kim JM: Giant axonal swelling in "huffer's" neuropathy. Arch Neurol 1976;33:583-586.

19. Oryshkevich RS, Wilcox R, Jhee WH: Polyneuropathy due to glue exposure: case report and 16 year follow-up. Arch Phys M ed Rehabil 1986;67:827-828.

20. Passero S, Battistini N, Cioni R, Giannini F, Paradiso C, Battista F, Cardoncini F, Sartorelli E: Toxic polyneuropathy of shoe workers in Italy. A clinical, neurophysiological and follow-up study. Ital J Neurol Sci 1983;4:463-472.

21. Pastore C, Marhuenda D, Marti J, Cardona A: Early diagnosis of n-hexane-caused neuropathy. M uscle N erve 1994;17:981-986.

22. Paulson GW, Waylonis GW: Polyneuropathy due to $\mathrm{n}$-hexane. Arch Intern M ed 1976;136:880-882.

23. Perbellini L, Brugnone F, Gaffuri E: Neurotoxic metabolites of "commercial hexane" in the urine of shoe factory workers. Clin Toxicol 1981;18:1377-1385.

24. Rizzuto N, De Grandis D, Di Trapani G, Pasinato E: n-H exane polyneuropathy. An occupational disease of shoemakers. Eur Neurol 1980;19:308-315.

25. Scelsi R, Poggi P, Fera L, Gonella G: Toxic polyneuropathy due to $n$-hexane. A light and electron microscopic study of the peripheral nerve and muscle from three cases. J N eurol Sci 1980;47:779.

26. Schaumburg $\mathrm{HH}$, Berger AR: Human toxic neuropathy due to industrial agents, in Dyck PJ, Thomas PK, Griffin JW, Low PA, Poduslo JF (eds): Peripheral Neuropathy, 3rd ed. Philadelphia, Saunders, 1993, pp 1533-1548.

27. Schaumburg HH, Spencer PS: Clinical and experimental studies of distal axonopathy-a frequent form of brain and nerve damage produced by environmental chemical hazards. Ann NY Acad Sci 1979;329:14-29.

28. Schaumburg HH, Spencer PS: Degeneration in central and peripheral nervous system produced by pure $n$-hexane: an experimental study. Brain 1976;99:183-192.

29. Seppalainen AM, Raitta C: N eurotoxic properties of $n$-hexane among occupationally exposed workers, in Proceedings of the Second Finnish-Estonian Symposium on Early Effects of Toxic Substances. 1981, pp 180-187.

30. Shirabe T, Tsuda T, Terao A, Araki S: Toxic polyneuropathy due to glue-sniffing. Report of two cases with a light and electron-microscopic study of the peripheral nerves and muscles. J Neurol Sci 1974;21:101-113.

31. Towfighi J, Gonatas NK, Pleasure D, Cooora HS, McCree L: Glue sniffer's neuropathy. N eurology 1976;26:238-243.

32. Wada Y, Okamoto S, Takagi S: Toxication polyneuropathy following $n$-hexane. Clin Neurol 1965;5:591.

33. Yamada S: An occurrence of polyneuritis by $n$-hexane in the polyethylene laminating plants. Jpn J Industrial H ealth 1964;6: 182.

34. Yamada S: Intoxication polyneuritis in the workers exposed to n-hexane. Jpn J Industrial H ealth 1967;9:651-659. 